\title{
Patient selection in ambulatory anesthesia - An evidence-based review: part II
}

\section{[La sélection des patients en anesthésie ambulatoire - Une revue factuelle : partie II]}

Gregory L. Bryson MD FRCPC MSc, ${ }^{*}$ Frances Chung MB FRCPC, $†$ Robin G. Cox MB BS FRCA FRCPC,

Marie-Josée Crowe MD FRCP, $\$$ John Fuller MD FRCPC, $\mathbb{I}$ Cynthia Henderson MD FRCPC,

Barry A. Finegan MB FRCPC, ** Zeev Friedman MD, †† Donald R. Miller MD FRCPC, ${ }^{*}$

Janet van Vlymen MD FRCPC, $\ddagger$ for the Canadian Ambulatory Anesthesia Research and Education (CAARE) Group

Purpose: This is the second of two reviews evaluating the management of patients with selected medical conditions undergoing ambulatory anesthesia and surgery. Conditions highlighted in this review include: diabetes mellitus; morbid obesity; the ex-premature infant; the child with an upper respiratory infection; malignant hyperthermia; and the use of monoamine oxidase inhibitors.

Source: Medline search strategies and the framework for the evaluation of clinical evidence are presented in Part I.

Principal findings: Diabetes mellitus has not been linked with adverse events following ambulatory surgery. The morbidly obese patient is at an increased risk for minor respiratory complications in the perioperative period but these events do not increase unanticipated admissions. The ex-premature infant may be considered for ambulatory surgery if post-conceptual age is $>60$ weeks and hematocrit is $>30 \%$. The child with a recent upper respiratory tract infection is at an increased risk for perioperative respiratory complications, particularly if endotracheal intubation is required. Patients with malignant hyperthermia may undergo outpatient surgery but require four hours of postoperative temperature monitoring. Sporadic cases of drug interactions have been reported when meperidine and indirectacting catecholamines are administered in the presence of monamine oxidase inhibitors. Ambulatory anesthesia and surgery is safe if these combinations of drugs are avoided.

Conclusion: Ambulatory anesthesia can be performed in, and is being offered to, a variety of patients with significant coexistent disease. In many cases there is little evidence documenting the outcomes expected in such patients. Prospective observational and interventional trials are required to better define perioperative management.
Objectif : C'est la seconde revue qui évalue la prise en charge de patients, dont les pathologies médicales ont été ciblées, qui doivent subir une anesthésie en chirurgie ambulatoire. Les situations choisies comprennent : le diabète, l'obésité morbide, l'enfant né prématurément, l'enfant atteint d'infection des voies respiratoires supérieures, l'hyperthermie maligne et l'usage d'inhibiteurs de la monoamine-oxydase.

Source : Les stratégies de recherche dans Medline et le cadre de l'évaluation de la preuve clinique sont présentés dans la partie $I$.

Constatations principales : Le diabète n'a pas été relié à des événements indésirables à la suite d'une opération ambulatoire. Le patient très obèse est plus à risque de complications respiratoires périopératoires mineures, ce qui n'augmente pas les admissions hospitalières imprévues. L'enfant prématuré est admis en chirurgie ambulatoire si l'âge post-conception est > 60 semaines et si l'hématocrite est > $30 \%$. L'enfant qui a une infection récente des voies respiratoires supérieures est plus à risque de complications respiratoires périopératoires, surtout si l'intubation endotrachéale est requise. Le patient souffrant d'hyperthermie maligne est admis en chirurgie ambulatoire, mais nécessite quatre heures de monitorage postopératoire de la température. Des cas sporadiques d'interactions de médicaments ont été signalés quand la mépéridine et des catécholamines à action indirecte sont administrées en présence d'inhibiteurs de la monoamine-oxydase. En l'absence de ces combinaisons, l'anesthésie et la chirurgie ambulatoires sont sans risque.

Conclusion : L'anesthésie ambulatoire peut être réalisée chez divers patients qui présentent des affections coexistantes importantes. Elle leur est d'ailleurs offerte. Dans de nombreux cas, il y a peu de preuve documentant l'évolution postopératoire attendue chez ces patients. Des études prospectives observationnelles et interventionnelles sont nécessaires pour mieux définir la prise en charge périopératoire.

From the Department of Anesthesiology, The Ottawa Hospital, ${ }^{*}$ Ottawa, Ontario; Department of Anesthesia, Toronto Western Hospital, $\dagger$ Toronto; Ontario; Department of Anesthesia, Alberta Children’s Hospital,ł Calgary, Alberta; Département d'Anesthésiologie, Hôpital Ste-Justine, $\$$ Montréal, Québec; Department of Anesthesia and Perioperative Care, St. Joseph’s Health Care, I London, Ontario; Department of Anesthesia, Vancouver General Hospital, Vancouver, British Columbia; Department of Anesthesiology and Pain Medicine, University of Alberta, ${ }^{* *}$ Edmonton, Alberta; Department of Anesthesia, Mount Sinai Hospital,†† Toronto, Ontario; Department of Anesthesiology, Kingston General Hospital, łł Kingston, Ontario, Canada.

Address correspondence to: Dr. Gregory L Bryson, Department of Anesthesiology, Head, Pre-Admission Units, The Ottawa Hospital, 1053 Carling Avenue, Ottawa, Ontario KIY 4E9, Canada. Phone: 613-761-4169; Fax: 613-761-5209;

E-mail:glbryson@ottawahospital.on.ca

Meeting facilities were sponsored by Purdue Pharma.

Accepted for publication February 2, 2004

Revision accepted May 14, 2004. 


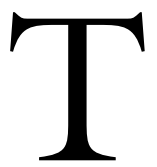

HIS is the second of two articles from the Canadian Ambulatory Anesthesia Research and Education (CAARE) Group discussing selection criteria for ambulatory surgery within an evidence-based framework. Details of the methods employed and a summary of the Center for Evidence Based Medicine Levels of Evidence and Grades of Recommendation used in this article may be found in part I. ${ }^{1} \mathrm{~A}$ list of the individual articles cited and their Level of Evidence (Appendix A) may be found as Additional Material at www.cja-jca.org

\section{Diabetes mellitus Scenario}

You are asked to see a 28 -yr-old female prior to a laparoscopic ovarian cystectomy. She has had diabetes for 22 years complicated by retinopathy and peripheral neuropathy. She is taking gabapentin, metformin, and synthetic human insulin 30/70: $20 \mathrm{U}$ before breakfast and $14 \mathrm{U}$ prior to dinner.

\section{Discussion}

The Current World Health Organization estimates suggest that 2 million Canadians suffer from diabetes, a number expected to increase to 3.5 million over the next 30 years. $^{2}$ Diabetes is diagnosed if random fasting plasma glucose exceeds $11.1 \mathrm{mmol} \cdot \mathrm{L}^{-1}$ or repeated fasting plasma glucose exceeds $7.0 \mathrm{mmol} \cdot \mathrm{L}^{-1}$. Diabetes is now classified as type $l$ if resulting from pancreatic islet cell destruction and type 2 if associated with defective insulin secretion and insulin resistance. ${ }^{3}$

Disease states associated with diabetes render the diabetic at an increased risk of perioperative complications. ${ }^{4}$ Diabetics requiring insulin are at an increased risk [odds ratio (OR) 3.0, 95\% confidence interval (CI) 1.3-7.0] of perioperative cardiac complications. ${ }^{5}$ Critical respiratory events are more common [relative risk (RR) 2.08, 95\% CI 1.42-3.04] among diabetics. ${ }^{6}$ Wound infections are more prevalent in diabetics following both cardiac ${ }^{7}$ and noncardiac ${ }^{8}$ surgery. Blood glucose readings on the first postoperative day $>12.2$ $\mathrm{mmol} \cdot \mathrm{L}^{-1}$ are associated with a 2.7 fold increased risk of infection $(P<0.05){ }^{9}$

\section{Are diabetics at an increased risk of complications fol- lowing outpatient surgery?}

Despite the increased likelihood of complications in a variety of major surgical procedures, diabetes is not an independent predictor of morbidity ${ }^{10}$ or mortality ${ }^{11}$ following day case surgery. A univariate analysis identified diabetics to be at an increased risk (OR 2.0, 95\% CI 1.3-2.2) of unanticipated admission following ambulatory surgery. ${ }^{12}$ This finding did not, however, persist when other variables were accounted for. Diabetes per se does not predict adverse outcome following minor ambulatory surgery (grade A)

\section{Is this patient at particular risk of airway problems?}

A complication of unique concern to anesthesiologists is the diabetic "stiff joint syndrome." Glycosylation of collagen decreases mobility of the cervical spine and the temporomandibular joint and may increase the likelihood of difficult laryngoscopy and intubation. Stiffness of the fourth and fifth interphalangeal joints (the prayer sign) assessed using palm prints is a sensitive predictor of difficult intubation. ${ }^{13} \mathrm{~A}$ retrospective review of 725 patients undergoing renal or pancreatic transplantation found diabetics were at a fourfold increased risk of minimally to moderately difficult intubation. ${ }^{14}$ All were successfully intubated by conventional means. A large prospective cohort study associated diabetes with an increased risk of critical respiratory events but not difficult intubation. ${ }^{6,15}$ Individual diabetic patients may be at an increased risk of difficult laryngoscopy but this does not appear to apply to diabetics as a group (grade B).

\section{How long before surgery should the patient discontinue metformin?}

Lactic acidosis is an infrequent complication of metformin therapy with an estimated incidence of 0.03 per 1,000 patient years of treatment. Intercurrent illness associated with hypotension, hypoxia, renal insufficien$\mathrm{cy}$, and use of radiocontrast dye are suggested to increase the risk of acidosis. ${ }^{16} \mathrm{~A}$ recent editorial recommended that metformin be discontinued $48 \mathrm{hr}$ before elective surgery. ${ }^{13}$ Published correspondence following the recommendation revealed that there is no evidence supporting 48-hr abstinence. ${ }^{17}$ A Cochrane review of 176 randomized controlled trials of metformin did not identify a single episode of lactic acidosis in over 35,000 patient-years of therapy. ${ }^{18}$ There have been no specific trials evaluating perioperative metformin withdrawal but systematic review suggests that metformin-related lactic acidosis is unlikely (grade B).

\section{Is there a preferred means of managing her insulin?}

Managing insulin therapy is a challenge for perioperative physicians. Patients randomly assigned to continuous $i v$ infusion of glucose-insulin-potassium following minor inpatient surgery had lower median blood glucose readings and were more likely to deliver readings in the target range of 5 to $10 \mathrm{mmol} \cdot \mathrm{L}^{-1}$ (48 vs 26\%) than those given insulin subcutaneously. ${ }^{19}$ These findings have not been supported in other trials involving a wider variety of surgical procedures. ${ }^{20-22}$ No trial has 
evaluated insulin regimens for the outpatient. For ambulatory procedures there is no evidence denoting superiority of $s c$ or $i v$ insulin replacement (grade D).

\section{Does choice of anesthetic technique influence periopera- tive glycemic control?}

Regional anesthesia blunts the increases in cortisol, glucagon, and glucose commonly seen following major surgery. ${ }^{23}$ Epidural blockade facilitates glucose uptake and reduces protein catabolism. ${ }^{24}$ It is surprising therefore to find only a single study comparing the influence of regional and general anesthesia on glycemic control in diabetics. Barker randomly assigned 20 patients with type 2 diabetes and 20 control patients to either regional or general anesthesia for cataract surgery. The use of regional anesthesia in both diabetic and control patients abolished the increase in glucose and cortisol seen in those patients undergoing general anesthesia. ${ }^{25}$ Extrapolation of these findings suggests that regional anesthesia may ameliorate the adverse effect of surgery on perioperative glycemic control (grade B).

\section{Conclusion - diabetes mellitus}

Diabetic patients are undoubtedly suitable for a variety of ambulatory surgical procedures. Comorbid conditions, including the difficult airway, must be identified and managed appropriately. Recommendations to withdraw metformin $>48 \mathrm{hr}$ preoperatively are not supported by evidence. Tighter control of perioperative glucose is encouraged. Administration of half of the patient's total morning insulin dose as an intermediate duration insulin with control of perioperative hyperglycemia using adjusted dose short- or ultra-short acting insulin provides glycemic control comparable to other more complex strategies.

\section{Morbid obesity}

Scenario

A 50-yr-old woman, $152 \mathrm{~cm}$ tall weighing $120 \mathrm{~kg}$, presents for ventral hernia repair. She has smoked one pack of cigarettes a day for the past 25 years. Other functional inquiry, physical examination, and electrocardiogram are normal. The surgeon would like perform the surgery on an outpatient basis.

\section{Discussion}

Obesity is defined as excess adipose tissue or body weight $>20 \%$ greater than ideal weight. Morbid obesity is defined as body weight more than twice the ideal weight. Taking the height in centimetres and subtracting 100 for men and 105 for women estimates ideal deal body weight in kilograms. ${ }^{26}$ Obesity may also be defined by the body mass index (BMI). BMI is calculated by dividing the body weight in kilograms by the square of the height in metres. Overweight is defined as BMI 25 to $30 \mathrm{~kg} \cdot \mathrm{m}^{-2}$, obesity as BMI $\geq 30$ $\mathrm{kg} \cdot \mathrm{m}^{-2}$, and morbid obesity as BMI $\geq 35 \mathrm{~kg} \cdot \mathrm{m}^{-2} \cdot{ }^{27}$

In 1992, the Royal College of Surgeons issued guidelines for ambulatory surgery. Patients with a BMI $>30 \mathrm{~kg} \cdot \mathrm{m}^{-2}$ were deemed unsuitable for operations performed on an ambulatory basis. ${ }^{28} \mathrm{~A}$ subsequent postal questionnaire of ambulatory surgery units within the United Kingdom revealed that $85 \%$ of the units surveyed were not adhering to the guidelines and anesthetized patients with a BMI $>30 \mathrm{~kg} \cdot \mathrm{m}^{-2} .{ }^{29}$ Canadian anesthesiologists also frequently provide ambulatory care for the morbidly obese. Ambulatory surgery for otherwise healthy patients with a $\mathrm{BMI}=$ 35 to $44 \mathrm{~kg} \cdot \mathrm{m}^{-2}$ and $\mathrm{BMI}>45 \mathrm{~kg} \cdot \mathrm{m}^{-2}$ was deemed acceptable by $91 \%$ and $50 \%$ of Canadian anesthesiologists, respectively. ${ }^{30}$ Unfortunately many obese patients are not "otherwise healthy."

A health survey found the prevalence of any cardiovascular diseases was $37 \%$ in adults with a BMI of $>30 \mathrm{~kg} \cdot \mathrm{m}^{-2}, 21 \%$ in those with a BMI of 25 to 30 $\mathrm{kg} \cdot \mathrm{m}^{-2}$, and only $10 \%$ in those with a BMI of $<25$ $\mathrm{kg} \cdot \mathrm{m}^{-2} \cdot{ }^{31}$ Hypertension and congestive heart failure are common among the obese because of increased cardiac output and blood volume. Approximately 5\% of morbidly obese patients have obstructive sleep apnea. ${ }^{32}$ The presence of cardiovascular or respiratory comorbidity significantly reduced willingness of Canadian anesthesiologists to provide ambulatory care to the obese. ${ }^{30}$ Ambulatory surgery for obese patients with cardiovascular or respiratory comorbidity was acceptable among $18 \%$ and $5 \%$ of anesthesiologists caring for patients with a BMI $=35$ to $44 \mathrm{~kg} \cdot \mathrm{m}^{-2}$ and $\mathrm{BMI}>45 \mathrm{~kg} \cdot \mathrm{m}^{-2}$, respectively. ${ }^{30}$

\section{Are the obese at an increased risk of adverse intraoper- ative events?}

In a cohort study of 17,638 patients, $2,779(15.9 \%)$ had a BMI $\geq 30 \mathrm{~kg} \cdot \mathrm{m}^{-2} \cdot{ }^{10}$ Patients in this study did not experience an excess of cardiovascular events despite the prevalence of cardiovascular disease in the obese. These patients were, however, at a significantly increased risk (OR 3.89; 95\% CI 1.14-13.3) of intraoperative respiratory events. Respiratory events complicated the course of approximately $1 \%$ of anesthetics given to obese patients. Desaturation and bronchospasm were most frequently noted. The RR of lower respiratory events was also significantly increased (RR 5.4, $P<0.01$ ) in obese members of a nearly 7,000 patient cohort undergoing ambulatory surgery. ${ }^{33}$ 
Rapid desaturation in apneic obese patients is caused by a decrease in their functional residual capacity (FRC). FRC decreases to an average of $1.9 \mathrm{~L}$ in obese males vs $2.6 \mathrm{~L}$ in lean subjects in the supine position. ${ }^{34}$ This decreased FRC reduces the time taken for oxygen saturation to decrease to $90 \%$ from six minutes in normal patients, to four minutes in obese patients, and $2.6 \mathrm{~min}$ in morbidly obese patients. ${ }^{35}$

While it is often assumed that the obese may be difficult to intubate, a study of 100 morbidly obese patients found that neither absolute obesity nor BMI was associated with intubation difficulties. ${ }^{36}$ Large neck circumference and increased Mallampati score were the only predictors of potential intubation problems. With a neck circumference of $40 \mathrm{~cm}$, the probability of a problematic intubation was approximately $5 \%$ and at $60 \mathrm{~cm}$, the probability of a problematic intubation was approximately $35 \%{ }^{36}$ The obese should be considered at an increased risk for intraoperative respiratory events (grade A).

\section{Are the obese at an increased risk of adverse postopera- tive events?}

Recovery room events of any kind are more frequent (RR 1.4, $P<0.01$ ) among obese patients. ${ }^{33}$ Respiratory events again predominate, occurring in approximately $1 \%$ of obese patients during their stay in the postanesthesia care unit (PACU)..$^{10}$ Obese patients were at a significantly higher risk of these events (RR $3.87 ; 95 \%$ CI 1.12-13.3) than their lean counterparts. ${ }^{10}$ Obese patients should therefore be considered at an increased risk of postoperative respiratory complications (grade A).

Are the obese at an increased risk of unanticipated hospital admission following ambulatory surgery?

Despite the prevalence of events among obese patients both in the operating room and during the early recovery period, ambulatory surgery seldom leads to significantly increased morbidity. In a study of 10,780 ambulatory surgery patients, $258(2.4 \%)$ were morbidly obese. There was no difference between the unplanned admission rate for a $\mathrm{BMI}>35 \mathrm{~kg} \cdot \mathrm{m}^{-2}$ and a $\mathrm{BMI}<35 \mathrm{~kg} \cdot \mathrm{m}^{-2} \cdot{ }^{37}$ There were no significant differences between the two groups with regard to unplanned contact with healthcare professionals after discharge. ${ }^{37}$ Three other large observational studies evaluating the outcomes of over 800,000 patients undergoing ambulatory surgery could find no association between obesity and unanticipated admission. ${ }^{11,12,38}$ There is no evidence that obesity alone contributes to unanticipated admissions following ambulatory surgery (grade A).

\section{Conclusion - morbid obesity}

Our patient is an otherwise healthy morbidly obese 50 -yr-old with a BMI of $52 \mathrm{~kg} \cdot \mathrm{m}^{-2}$. Her obesity places her at an increased risk of intraoperative desaturation and bronchospasm. Both obesity and smoking ${ }^{10}$ place her at an increased risk of postoperative respiratory events. Fortunately none of these complications appear to increase the risk of unanticipated admission suggesting they are minor and reversible in nature. Outpatient surgery is a reasonable alternative for this morbidly obese patient if the increased risk of respiratory events is recognized and managed accordingly.

\section{The ex-premature infant}

\section{Clinical scenario}

You are asked to provide anesthesia for an infant requiring bilateral inguinal hernia repair. The hernia incarcerated three days previously and was difficult to reduce at that time. The baby was born at 32 weeks of gestational age and is now 28 weeks old, or 60 weeks post-conceptual age (PCA). The birth weight was $1850 \mathrm{~g}$ and the current weight is $4800 \mathrm{~g}$. Oxygen was required for the first two days of life but not since that time. There have been no documented apneic spells and the baby has been at home for the past 24 weeks. A recent blood count showed a hemoglobin of 105 $\mathrm{g} \cdot \mathrm{L}^{-1}$. The baby has been well and is on no medications apart from vitamins and iron. The surgeon would like to perform surgery on an outpatient basis.

\section{Discussion}

Inguinal hernia is a common finding in premature infants. The risk of developing a hernia increases with decreasing birth weight. ${ }^{39}$ Approximately $9 \%$ of children with inguinal hernia incarcerate with consequent risk to bowel and gonads. Of those patients with incarceration $85 \%$ are under one year of age. ${ }^{40}$ Surgery is therefore generally performed on an expedited basis, often before the physiologic effects of prematurity have passed. In the scenario described, the hernia had incarcerated previously and there is a strong likelihood that this will recur if not repaired.

\section{What factors predict the occurrence of postoperative apnea?}

The risk of postoperative apnea has been evaluated in a number of studies, both retrospective and prospective. Coté pooled individual patient data from $255 \mathrm{ex}-$ premature infants in eight prospective studies ${ }^{41}$ and calculated the probability of postoperative apnea occurring using a logistic regression model. Postoperative apnea occurred in approximately $25 \%$ of these patients. The likelihood of apnea was inversely 
related to both gestational age and PCA. Apnea occurred in fewer than $5 \%$ of patients 60 weeks PCA regardless of gestational age. A hematocrit $<30 \%$ was significantly correlated with the likelihood of apnea, particularly in those children greater than 43 weeks PCA. Assuming no apnea was witnessed in the PACU and a hematocrit $>30 \%$, a 60 -week PCA infant undergoing herniorrhaphy could be expected to experience apnea in less than $<0.05 \%$ of cases.

Several points arise from Coté's analysis. Firstly, the eight clinical studies that contributed to these data were published between 1987-1993. Anesthetic techniques have advanced somewhat since that period when halothane and muscle relaxants were the norm. Secondly, marked differences in the incidence of postoperative apnea were noted in the various centres likely related to differences in monitoring technology. Thirdly, the risk for postoperative apnea gradually declined with advancing age, but there was no point at which risk was absent. Fisher in his accompanying editorial also questions "whether a consistent policy regarding postoperative disposition of these patients can be determined based on current information." 42 Although it is known that gestational age, PCA, and anemia are significant predictors of postoperative apnea (grade A), the risks and benefits of an ambulatory procedure should nevertheless be evaluated for each individual patient.

\section{How long should the patient be monitored in the PACU?}

Since Coté's analysis was published, other reports have been written. Most of these evaluate the benefits of regional anesthesia (spinal or caudal) in ex-prematures. One study did seek to evaluate the factors that are associated with postoperative complications in exprematures as well as the safe period for postoperative observation. ${ }^{43}$ Based upon this retrospective review of 57 patients, the authors concluded that "outpatient inguinal herniorrhaphy under general anesthesia in the ASA class I ex-premature infant is safe" and recommend a six- to eight-hour period of monitoring. They make this claim despite the retrospective nature of their study and the fact that $8.8 \%$ of their subjects failed extubation. Furthermore, few pediatric anesthesiologists would designate an ex-premature baby as ASA class I. The optimal length of PACU monitoring is therefore poorly defined (grade C).

\section{Can the baby's medical condition be improved preoper- atively?}

In the case of our patient, the baby is generally well, is not anemic by Coté's definition and is at a PCA at which the risk for postoperative apnea should be negligible. There is no benefit in delaying surgery, as incarceration of the hernia has already occurred. A hemoglobin level of $105 \mathrm{~g} \cdot \mathrm{L}^{-1}$ is acceptable $\mathrm{e}^{41,44}$ and the baby is on an iron supplement already. Few anesthesiologists would recommend transfusion for mild to moderate anemia $\left(80-100 \mathrm{~g} \cdot \mathrm{L}^{-1}\right)$ in the absence of symptoms. From the viewpoint of postoperative apnea, it would seem that the baby could undergo surgery as an outpatient, assuming no intraoperative complications or apneic spells are encountered in the PACU (grade A). As pointed out by Sims ${ }^{45}$ however, very few infants older than 60 weeks PCA have been studied.

\section{Is caffeine indicated to reduce the risk of apnea?}

The influence of caffeine on the incidence of postoperative apnea was evaluated in 32 otherwise healthy ex-premature infants undergoing inguinal herniorrhaphy at $<44$ weeks PCA. Subjects were randomly assigned to caffeine $10 \mathrm{mg} \cdot \mathrm{kg}^{-1}$ iv or matching placebo. Caffeine-treated infants experienced no adverse events, compared to an $81 \%$ incidence of apnea and a $50 \%$ incidence of desaturation in those receiving placebo. ${ }^{46} \mathrm{~A}$ systematic review suggests that treatment with caffeine is associated with a $91 \%$ reduction in the RR of apnea (RR 0.91; 95\% CI 0.66-0.98) and an absolute risk reduction of $58 \%$. Only two patients would require caffeine to prevent one episode of apnea. ${ }^{47}$ Caffeine is undoubtedly helpful in reducing the risk of apnea in younger ex-premature infants but should not replace careful patient selection and appropriate monitoring (grade A).

\section{Is regional anesthesia the technique of choice?}

Awake regional techniques in the form of caudal ${ }^{48,49}$ or spinal ${ }^{50-56}$ anesthesia have been reported extensively. Many of these studies are case series. However, there are four randomized controlled trials comparing spinal with general anesthesia. ${ }^{50,53-55}$ Welborn noted a marked increase in the risk of apnea in patients undergoing spinal anesthesia with $i m$ ketamine premedication. Patients undergoing general anesthesia or spinal anesthesia without premedication had similar outcomes. ${ }^{50}$ Three other studies found an association between general anesthesia and postoperative desaturation, bradycardia, and apnea but all excluded randomized patients in whom spinal anesthesia was inadequate or could not be obtained. ${ }^{53-55}$ Withdrawal rates in these studies ranged from 11 to $28 \%$. Failure to follow an intention-to-treat methodology is a serious threat to the validity of these findings. Williams questions "routinely subjecting our patients to an 
awake technique that is potentially stressful for the infant and associated with a clinically significant failure rate." 55 To date no published direct comparison of spinal vs caudal anesthesia in this population has appeared in the literature. Postoperative apnea has been noted after both caudal ${ }^{57}$ and spinal ${ }^{58}$ anesthesia in ex-prematures, although these cases all involved infants with comorbidities. The choice of a regional or general anesthetic technique is best left to the individual anesthesiologist as the evidence does not favour one technique over the other (grade D). It would seem prudent to manage the postoperative care in the same fashion, irrespective of whether a regional or general technique is used.

\section{Conclusion - the ex-premature infant}

In summary, this infant could be managed safely as an outpatient, assuming the perioperative environment is appropriate to handle such cases and there are no other factors (social, geographic, etc.) that would make an admission desirable. The case presented has a very low risk for postoperative apnea, therefore there is no strong indication for caffeine therapy or avoidance of general anesthesia. Many pediatric anesthesiologists would provide postoperative analgesia with a caudal or ilioinguinal block; there is, however, no evidence linking this practice with outcomes.

\section{The child with an upper respiratory infection (URI) Clinical scenario}

Your next patient is an otherwise healthy five-year-old scheduled for tonsillectomy and adenoidectomy. There is no asthma or evidence of sleep apnea but the child snores. He has never had an anesthetic and there is no family history of anesthesia problems. The child had a URI with fever and systemic symptoms approximately two weeks ago. He had copious but clear nasal discharge. He no longer has a fever, his appetite has returned, and his rhinorrhea has resolved. He has a non-productive cough but his lungs are clear to auscultation.

\section{Discussion}

URI is one of the most frequently discussed issues between anesthesiologists, surgeons and parents. Identifying the child with URI is surprisingly difficult as symptoms of URI are non-specific and shared with allergies and other conditions. Most researchers define URI as a minimum of two of the following symptoms (sore or scratchy throat, sneezing, rhinorrhea, nasal congestion, malaise, cough, fever, laryngitis) together with confirmation by a parent. ${ }^{59-61}$ The definition of fever has been a moving target; initially described as $\geq$
TABLE Characteristics associated with respiratory complications in the child with URI

\begin{tabular}{ll}
\hline Tait $^{62}$ & Parnis $^{63}$ \\
\hline Endotracheal intubation & Endotracheal intubation \\
Second hand smoke & Second hand smoke \\
Nasal congestion & Nasal congestion \\
Copious secretions & Productive cough \\
History of reactive airway disease & Parent states child has URI \\
History of prematurity $(<37$ weeks $)$ & Parent states child snores \\
Surgery involving the airway & Thiopental \\
& Failure to reverse muscle \\
& relaxants \\
\hline
\end{tabular}

$\mathrm{URI}=$ upper respiratory infection.

$38.3^{\circ} \mathrm{C}^{59}$ it was then redefined as either equal to $38.0^{\circ} \mathrm{C}^{62}$ or $>38.0^{\circ} \mathrm{C}^{63}$ in recent literature. Ill-looking, lethargic children and those with high fever, purulent nasal discharge, or signs of lower respiratory infection are unsuitable for elective surgery and are excluded from published studies in this field. Children under one year of age were also frequently excluded from these studies, limiting one's conclusions to older children.

\section{Is the child with URI at an increased risk of periopera- tive complications?}

A large prospective cohort study of over 17,000 children identified an association between URI and an increased risk (OR 8.94; 95\% CI 6.14-13.22) of perioperative respiratory events. ${ }^{64}$ Endotracheal intubation in combination with URI symptoms further increased the risk of events (OR 11.13; 95\% CI 6.84-18.10). No other events were influenced by URI. What sort of events are associated with URI? In Cohen's study events are described as either airway obstruction, croup, or "other airway" events. Several other prospective cohort studies provide more rigorous definitions. These cohorts suggest a two- to threefold increase in the RR of transient desaturation in the perioperative period. ${ }^{62,65-67}$ Desaturation was variably defined as saturations $<95 \%$ to $<90 \%$. A single study that distinguished minor desaturations $(\leq 95 \%)$ from major desaturations $(\leq 85 \%)$ found no association between URI and the more significant events. ${ }^{67}$ No relationship between URI symptoms and laryngospasm and bronchospasm was found in a prospective cohort of over 1,000 children; however, the likelihood of breath holding and cough were increased. ${ }^{62}$ On the other hand, a case-control study of 123 patients with laryngospasm and 492 matched controls found parental report of URI was associated 
with a doubling (OR 2.05; 95\% CI 1.21-3.45) of the odds of developing laryngospasm. ${ }^{60}$ Children managed by inexperienced anesthesia staff were nearly twice as likely (OR 1.75; 95\% CI 108-2.86) to develop laryngospasm. In summary, current URI symptoms increase the risk of perioperative respiratory events. Desaturation, coughing, and breath holding events are the most consistently reported (grade A).

\section{How serious are the respiratory complications associated with URI?}

Studies grading the severity of respiratory events found significant increases in the severity of surrogate events such as cough, breath holding, and secretions. ${ }^{62,66,68}$ Episodes of laryngospasm or bronchospasm in these studies were no more frequent or severe in those with URI. True outcomes such as unanticipated hospital admission, pneumonia, and death were rare. Of the nearly 1,300 children in these studies only two were admitted to hospital with pneumonia and two were treated for stridor. The majority of respiratory events associated with URI are transient and relatively minor in nature (grade A).

\section{Does airway management influence outcome?}

Cohen's large cohort study identified endotracheal intubation as a significant predictor (OR 5.21;95\% CI 4.21-6.46) of perioperative respiratory complications in all children regardless of URI status. ${ }^{64}$ Tait randomly assigned 82 children with current URI symptoms to receive either endotracheal intubation or a laryngeal mask airway (LMA). Patients managed with an endotracheal tube were significantly more likely to experience bronchospasm and desaturation during intubation than those managed with a LMA.68 Endotracheal intubation increases the risk of respiratory events in the perioperative period (grade A).

\section{How long after an URI should surgery be delayed?}

Studies traditionally defining "recent" URI as "symptoms within the past two weeks" noted similar incidences of respiratory events in those with current and recent URIs. ${ }^{60,66}$ In Tait's prospective cohort of over 1,000 children the definition of "recent" was extended to four weeks. The incidence of adverse respiratory events was $30 \%$ in the active URI group, $24.2 \%$ in those with symptoms in the past four weeks, and $18 \%$ in the control group. ${ }^{62}$ Should these findings be repeated it would appear that a four-week delay following resolution of URI symptoms may be required to reduce patient risk (grade B).
Can the child at risk for complications be identified?

Two cohort studies evaluating risk factors for perioperative respiratory complications in over 3,000 children with URI symptoms have been published. ${ }^{62,63}$ Characteristics associated with respiratory events are shown in the Table. Features common to models such as endotracheal intubation, second hand smoke, nasal congestion, and productive cough/secretions highlight the child with URI in whom respiratory events should be anticipated (grade A).

\section{Conclusion - the child with an URI}

This five-year-old patient with no history of sleep apnea is a candidate for tonsillectomy on an outpatient basis. URI symptoms within the past four weeks place him at an increased risk of minor perioperative respiratory events. These events should not contraindicate anesthesia when perioperative care is managed by an experienced anesthesiologist. However, the further risks associated with airway surgery and endotracheal intubation should be weighed against the benefits of a four-week delay. A frank discussion with the parents should highlight the risks of proceeding at this time.

\section{Malignant hyperthermia ( $\mathrm{MH})$ Scenario}

You have been asked to provide anesthesia for a tympanoplasty to be performed as same day surgery on a nine-year-old girl. She belongs to a family with a strong history of $\mathrm{MH}$. A paternal uncle suffered a $\mathrm{MH}$ crisis and your patient's father is biopsy positive for $\mathrm{MH}$. She is otherwise healthy.

\section{Discussion}

How long should the patient be monitored postoperatively?

Yentis et al. reviewed the charts of 431 anesthetics in $303 \mathrm{MH}$ susceptible (MHS) children given non-triggering anesthetics. ${ }^{69}$ Ten of the children $(3.5 \%)$ developed postoperative pyrexia but none of these were considered to be $\mathrm{MH}$. The authors recommend that MHS is not an indication for postoperative hospital admission. Two retrospective case series document the development of $\mathrm{MH}$ in eight patients within five hours of a non-triggering anesthetic. Grinberg reports the development of postoperative fever in three patients with family histories suspicious of $\mathrm{MH}^{70}$ while Carr reports five patients with fever in a group of 2,214 patients undergoing muscle biopsy for MHS. ${ }^{71}$ All of the reactions occurred in the immediate postoperative period, in the recovery room. Applying the MH clinical grading scale ${ }^{72}$ to the clinical details available in these reports only two of these reactions were 
"very likely" to be $\mathrm{MH}$; the other six were evenly split between "somewhat less than" or "somewhat more than" likely to be $\mathrm{MH}$. The incidence of $\mathrm{MH}$ triggering in MHS patients undergoing a non-triggering anesthetic has been estimated to be less than $1 \%{ }^{71,73}$ The Malignant Hyperthermia Association of the United States (MHAUS) advises that the MHS patients may be discharged three to five hours following an uneventful anesthetic. ${ }^{74}$ The Malignant Hyperthermia Association of Canada (MHA Canada) recommends a four-hour monitoring period. ${ }^{75}$ There is no contraindication to ambulatory anesthesia for MHS patients as long as a minimum of four hours of postoperative monitoring can be performed (grade C). As many ambulatory surgical centres close in the early evening, scheduling of MHS patients must take postoperative monitoring considerations into account.

\section{Is patient age a risk factor for $M H$ triggering in $M H S$ patients?}

The incidence of $\mathrm{MH}$ is estimated to be higher in children $(1: 15,000)$ than in adults $(1: 50,000) .{ }^{76}$ Strazis and Fox reviewed 336 publications of 503 case reports of $\mathrm{MH} .{ }^{77}$ Mean age of reported cases was $18.3 \mathrm{yr}$. Children aged less than 15 comprised $52 \%$ of the reported cases, and age did not increase the risk of $\mathrm{MH}$. A study of patients undergoing biopsy for $\mathrm{MH}$ testing documented a mean age of $32.5 \mathrm{yr}^{71}$ Five patients with postoperative fever were ages three, 12 , 15,24 , and 26 . Yentis et al. studied only children, aged two months to $19 \mathrm{yr}$ and do not document any age-related findings. ${ }^{69}$ There is no clear evidence of an elevated risk of $\mathrm{MH}$ triggering, morbidity or mortality in MHS children (grade C).

\section{Is the duration of surgery a risk factor?}

None of the aforementioned publications specifically sought a relationship between the duration of surgery and anesthesia and the likelihood of triggering. The data in those publications do not indicate an association between risk of $\mathrm{MH}$ and the duration of surgery (grade C).

\section{Is the type of surgery a risk factor?}

Strazis documents a preponderance of case reports of $\mathrm{MH}$ in patients undergoing ear, nose and throat, dental and eye surgery, which may simply reflect the increased incidence of $\mathrm{MH}$ in children. ${ }^{69}$ There may be a higher risk of MHS in patients with hereditary musculoskeletal syndromes. ${ }^{78}$ However, Strazis' article does not indicate a higher fatality rate in any of these groups. There is no clear evidence of an increased risk by type of surgery for MHS patients (grade C).
Is postoperative fever an indication for hospital admission?

Ongoing monitoring is indicated for MHS patients demonstrating clinical signs of MH. In Yentis' study ten suspected MHS children developed postoperative pyrexia greater than $38.5^{\circ} \mathrm{C} .{ }^{69}$ None of these progressed to $\mathrm{MH}$. The five patients with postoperative fever considered by Carr to have had $\mathrm{MH}$ all demonstrated temperatures above $38^{\circ} \mathrm{C}^{71}$ Unfortunately this study failed to document whether pyrexia occurred in other patients. The rate of rise of temperature is of greatest significance, rising as fast as $1{ }^{\circ} \mathrm{C}$ in five minutes in a $\mathrm{MH}$ crisis. ${ }^{79}$ There is little available evidence to support recommendations for the management of isolated postoperative pyrexia in MHS patients but admission to hospital for observation is advised by authorities (grade D). ${ }^{74,75}$

\section{Conclusions - MH}

$\mathrm{MH}$ is a rare condition and does not lend itself to large prospective studies. Knowledge of this condition and its management in the ambulatory setting is largely derived from case reports and retrospective reviews of cases. This low level of evidence is reflected in the grades of recommendations. However, authorities support ambulatory procedures in MHS patients as long as a minimum of four hours of temperature monitoring can be provided postoperatively. MHAUS and MHA Canada recommendations suggest that the patient described can safely undergo ambulatory surgery with a non-triggering anesthetic. She will be monitored closely postoperatively for four hours, and her parents given clear instructions describing symptoms that should prompt a return to the hospital.

\section{Monoamine oxidase inhibitors (MAOI) \\ Scenario}

A 45-yr-old woman with recurrent depression is scheduled for nasoseptorhinoplasty in a freestanding ambulatory surgery centre. Past medical history includes severe depression, treated with tranylcypromine. Recent psychiatric evaluation reveals that the patient is stable, but at a high risk for relapse if her MAOI is withdrawn. Discontinuation of her MAOI two weeks prior to surgery was discussed with the patient but she refused. Her surgery requires either topical cocaine or an epinephrine containing local anesthetic for hemostasis.

\section{Discussion}

MAOI increase brain monoamines and cytoplasmic concentration of MAO substrates by inhibiting metabolism of cytoplasmic neurotransmitters. ${ }^{80}$ 
Classic MAOI, phenelzine and tranylcypromine, irreversibly inhibit MAO for two to three weeks until a new enzyme is synthesized. ${ }^{80}$ Moclobemide, a reversible inhibitor of MAO-A (RIMA) causes enzyme inhibition for less than $24 \mathrm{hr}^{81,82}$ Selegiline, an antiParkinsonian agent, is a short-acting, reversible MAO$\mathrm{B}$ inhibitor at its usual dose..$^{83}$

\section{What is the evidence linking MAOI to serotonergic crises?}

Serotonergic reactions to meperidine have been described for all MAOI ${ }^{80,84,85}$ including moclobemide ${ }^{81,82}$ and selegiline. ${ }^{83}$ Meperidine blocks neuronal serotonin reuptake, resulting in serotonergic overactivity, agitation, hyper/hypotension, convulsions, hyperthermia, and coma. ${ }^{82}$ However, serotonin concentration must reach a critical level, as evidenced by one patient who reacted to meperidine only after increasing her phenelzine dose $^{80}$ and by a randomized, controlled trial, in which 15 patients on MAOI given meperidine and morphine all responded normally. ${ }^{85}$ Cocaine also reduces serotonin inactivation and blocks monoamine reuptake. ${ }^{80,86} \mathrm{~A}$ delayed excitatory reaction occurred in a patient on phenelzine $70 \mathrm{~min}$ after topical laryngeal cocaine. ${ }^{86}$ Serotonergic crises may follow the administration of meperidine or cocaine (grade C).

Are MAOI associated with atypical responses to all catecholamines?

Elevated preganglionic MAO substrates can cause an exaggerated response to indirect-acting sympathomimetics as long as three weeks after classic MAOI are discontinued. ${ }^{80} \mathrm{~A}$ patient on selegiline developed hypertension and supraventricular tachycardia after receiving ephedrine ${ }^{87}$ whereas a patient who omitted one dose of moclobemide responded normally to both phenylephrine and ephedrine. ${ }^{81}$ Indirect-acting catecholamines should be avoided (grade C).

Although it has been recommended to avoid epinephrine-containing solutions, ${ }^{80}$ there is no evidence to support this. In fact, direct-acting sympathomimetics such as epinephrine are the recommended pressor agents for patients on MAOI. ${ }^{80,84}$ Patients on MAOI/RIMA do not have clinically significant potentiation of cardiovascular effects of $i v$ infusions of norepinephrine or epinephrine. ${ }^{82,88}$ Vasopressors at concentrations contained in local anesthetics are not likely to be significantly potentiated in otherwise healthy patients on MAOI. ${ }^{88}$ Direct-acting sympathomimetics may be used safely (grade C).

Do MAOI interact with anesthetic drugs?

MAOI inhibit microsomal enzymes, theoretically potentiating barbituates and opioids. ${ }^{80}$ Three cases of excessive barbiturate/opioid effects were reported from 1960 to $1970 .{ }^{80,84}$ Since then, numerous reports have described uneventful anesthetics using barbiturates and various opioids: remifentanil, ${ }^{89}$ alfentanil, ${ }^{89,90}$ sufentanil, ${ }^{91}$ fentanyl, ${ }^{80,81}$ hydromorphone ${ }^{91}$ and morphine ${ }^{80,81,81,85,89}$ for patients continuing to take MAOI. Other agents including propofol, ${ }^{90,92}$ ketamine, ${ }^{93}$ midazolam, ${ }^{92}$ ketorolac, ${ }^{92}$ vecuronium, ${ }^{92}$ and atracurium ${ }^{92}$ have also been used safely. Severe hypertension on induction with etomidate and atracurium has occurred, although the patient's blood pressure was $200 / 90$ immediately prior to induction..$^{94}$ Regional anesthesia has been performed without incident when hypotension was treated appropriately with volume and direct-acting sympathomimetics. ${ }^{80,81,95,96}$ Normal responses to most anesthetic agents can be expected (grade C).

\section{Is the continuation of MAOI associated with adverse outcomes?}

Much of our understanding of the interactions between MAOI and anesthetic drugs comes from reports of isolated events in individual patients. A controlled prospective evaluation of 27 patients chronically treated with MAOI undergoing 36 anesthetics reported no adverse cardiovascular responses. ${ }^{95}$ Changes in blood pressure and heart rate were not significantly different from control patients without prior MAOI exposure. Anesthetic agents included sodium thiopental, etomidate, diazepam, succinylcholine, nitrous oxide, volatiles, pancuronium, morphine, spinal tetracaine, epidural bupivacaine, and phenylephrine. ${ }^{95}$ Similarly a review of a series of 32 orthopedic patients on MAOI who underwent 46 general anesthetics and five regional anesthetics for elective surgery found no adverse hemodynamic events. ${ }^{96}$ Agents used in this series included sodium thiopental, ketamine, volatiles, morphine and meperidine. Aside from sporadic case reports, the continued use of MAOI/RIMA has not been associated with adverse perioperative events when meperidine and indirect acting catecholamines are avoided (grade B).

\section{Conclusion - MAOI}

Case reports of sporadic MAOI-related drug interactions prompted many to advise discontinuation of classic MAOI two to three weeks before surgery. ${ }^{80,84,95}$ Withdrawal of MAOI is not without risks. Many patients have severe depression refractory to other treatment and are at risk for life-threatening psychiatric illness. Acute exacerbation of depression with suicidal ideation has been reported after discontinuation 
of MAOI prior to elective cardiac surgery. ${ }^{97}$ There is no literature specifically concerning MAOI and ambulatory anesthesia. MAOI-related drug interactions are possible and have been reported; however, patients continuing to take either classic or selective MAOI remain suitable candidates for ambulatory anesthesia if meperidine, cocaine and indirect-acting catecholamines are avoided.

\section{Summary}

To date much of the research in ambulatory anesthesia has focused on selection of anesthetic techniques to minimize side effects in the healthy outpatient. This series of brief evidence-based reviews highlights what is known and what is yet to be learned regarding selected high-risk patients undergoing ambulatory surgery. For many patient conditions the clinician must base his/her practice on case reports or extrapolate conclusions from more invasive inpatient procedures. This need not be so.

Level 1 evidence characterizes the incidence and risk factors predicting postoperative apnea in the expremature infant undergoing herniorrhaphy. The clinician can call on randomized controlled trials to inform the choice of regional or general anesthesia and systematic review to summarize the prophylactic use of caffeine. Compare this to our knowledge of outcomes in adult patients with sleep apnea. A single retrospective study of patients with sleep apnea and matched controls undergoing ambulatory surgery is available to guide the clinician. Anesthesiologists should have better answers to these and other questions they are faced with in their ambulatory practice.

Research in ambulatory anesthesia should now focus on identifying the risks and benefits of this model of care. Events following discharge in higher risk subgroups of patients should be sought and characterized. Prospective trials to characterize the patient at risk for complications and strategies to reduce these events are required. Ambulatory surgery has moved well beyond the "ASA I and II" patient that is represented in much of our prospective literature. Research in ambulatory anesthesia must follow.

\section{Acknowledgements}

The Canadian Ambulatory Anesthesia Research and Education (CAARE) Group would like to thank Dr. Ramiro Arellano, Dr. Peter Duncan, Dr. Angela Fitzmaurice, Dr. Ken LeDez, Dr. Stuart McCluskey, Dr. Barbara Pask, Dr. Donald Wilson, and Dr. Suntheralingam Yogendran for their participation. Special thanks to Alexandra Davis for her assistance with the literature searches.

\section{References}

1 Bryson GL, Chung F, Finegan BA, et al. Patient selection in ambulatory anesthesia - An evidence-based review: part I. Can J Anesth 2004; 51: 768-81.

2 World Health Organization. Total of people with diabetes. 2003; available from URL; http://www.who.int/ncd/dia/databases4.htm.

3 World Health Organization Department of Noncommunicable Disease Surveillance. Diagnosis, definition, and classification of diabetes mellitus and its complications. 1999; available from URL; http://whqlibdoc.who.int/hq/1999/WHO_NCD_N CS_99.2.pdf.

4 McAnulty GR, Robertshaw HJ, Hall GM. Anaesthetic management of patients with diabetes mellitus. $\mathrm{Br}$ J Anaesth 2000; 85: 80-90.

5 Lee TH, Marcantonio ER, Mangione CM, et al. Derivation and prospective validation of a simple index for prediction of cardiac risk of major noncardiac surgery. Circulation 1999; 100: 1043-9.

6 Rose DK, Cohen MM, Wigglesworth DF, DeBoer DP. Critical respiratory events in the postanesthesia care unit: patient, surgical, and anesthetic factors. Anesthesiology 1994; 81: 410-8.

7 Kobli M, Yuan L, Escobar M, et al. A risk index for sternal surgical wound infection after cardiovascular surgery. Infect Control Hosp Epidemiol 2003; 24: 17-25.

8 Malone DL, Genuit T, Tracy JK, Gannon C, Napolitano LM. Surgical site infections: reanalysis of risk factors. J Surg Res 2002; 103: 89-95.

9 Pomposelli JJ, Baxter JK III, Babineau TJ, et al. Early postoperative glucose control predicts nosocomial infection rate in diabetic patients. JPEN J Parenter Enteral Nutr 1998; 22: 77-81.

10 Chung F, Mezei G, Tong D. Pre-existing medical conditions as predictors of adverse events in day-case surgery. Br J Anaesth 1999; 83: 262-70.

11 Fleisher LA, Pasternak R, Lyles A. A novel index of elevated risk for hospital admission or death immediately following outpatient surgery. Anesthesiology 2002; 96: A38 (abstract).

12 Fortier J, Chung F, Su J. Unanticipated admission after ambulatory surgery-a prospective study. Can J Anaesth 1998; 45: 612-9.

13 Nadal JL, Fernandez BG, Escobar IC, Black M, Rosenblatt $W H$. The palm print as a sensitive predictor of difficult laryngoscopy in diabetics. Acta Anaesthesiol Scand 1998; 42: 199-203.

14 Warner ME, Contreras MG, Warner MA, Schroeder DR, Munn SR, Maxson PM. Diabetes mellitus and difficult laryngoscopy in renal and pancreatic transplant patients. Anesth Analg 1998; 86: 516-9. 
15 Rose DK, Cohen MM. The airway: problems and predictions in 18,500 patients. Can J Anaesth 1994; 41(5 Pt 1): 372-83.

16 Bailey CJ, Turner RC. Metformin. N Engl J Med 1996; 334: 574-9.

17 Jones $P$, rate $P$. Contraindications to use of metformin. Blanket banning of metformin two days before surgery may not be a good idea (Letter). BMJ 2003; 326: 762 .

18 Salpeter S, Greyber E, Pasternak G, Salpeter E. Risk of fatal and nonfatal lactic acidosis with metformin use in type 2 diabetes mellitus. Cochrane Database Syst Rev 2002; 2: CD002967.

19 Christiansen CL, Schurizek BA, Malling B, Knudsen L, Alberti $K G$, Hermansen $K$. Insulin treatment of the insulin-dependent diabetic patient undergoing minor surgery. Continuous intravenous infusion compared with subcutaneous administration. Anaesthesia 1988; 43: 533-7.

20 Thomas DJ, Platt HS, Alberti KG. Insulin-dependent diabetes during the peri-operative period. An assessment of continuous glucose-insulin-potassium infusion, and traditional treatment. Anaesthesia 1984; 39: 629-37.

21 Pezzarossa A, Taddei F, Cimicchi MC, et al. Perioperative management of diabetic subjects. Subcutaneous versus intravenous insulin administration during glucose-potassium infusion. Diabetes Care 1988; 11: 52-8.

22 Taitelman U, Reece EA, Bessman AN. Insulin in the management of the diabetic surgical patient. Continuous intravenous infusion vs subcutaneous administration. JAMA 1977; 237: 658-60.

23 Lattermann R, Carli F, Wykes L, Schricker T. Epidural blockade modifies perioperative glucose production without affecting protein catabolism. Anesthesiology 2002; 97: 374-81

24 Schricker T, Wykes L, Carli F. Epidural blockade improves substrate utilization after surgery. Am J Physiol Endocrinol Metab 2000; 279: E646-53.

25 Barker JP, Robinson PN, Vafidis GC, Burrin JM, Sapsed-Byrne S, Hall GM. Metabolic control of noninsulin-dependent diabetic patients undergoing cataract surgery: comparison of local and general anaesthesia. Br J Anaesth 1995; 74: 500-5.

26 Adams JP, Murphy PG. Obesity in anaesthesia and intensive care. Br J Anaesth 2000; 85: 91-108.

27 rao FS, Savarese JJ. Morbid obesity in anesthesiology, problem-oriented patient management. In: Yao FS, Artusio JF Jr (Eds). Anesthesiology. Problem-Oriented Patient Management, 3rd ed. PA: Lippincott-Raven; 1998: 1001-19.

28 Commision on the Provison of Surgical Services. Guidelines for day case surgery. A report of the Royal
College of Surgeons of England, 1992.

29 Atkins M, White J, Abmed K. Day surgery and body mass index: results of a national survey. Anaesthesia 2002; 57: 180-2.

30 Friedman Z, Wong DT, Chung F. What are the ambulatory surgical patient selection criteria in Canada? Can J Anesth 2003; 50(Suppl): Al6 (abstract).

31 Lean ME. Obesity and cardiovascular disease: the waisted years. Br J Cardiol 1999; 6: 269-73.

32 Young T, Palta M, Dempsey J, Skatrud J, Weber S, Badr $S$. The occurrence of sleep-disordered breathing among middle-aged adults. N Engl J Med 1993; 328: 1230-5.

33 Duncan PG, Cohen MM, Tweed WA, et al. The Canadian four-centre study of anaesthetic outcomes: III. Are anaesthetic complications predictable in day surgical practice? Can J Anaesth 1992; 39(5 Pt 1): 440-8.

34 Tucker DH, Sieker HO. The effect of change in body position on lung volumes and intrapulmonary gas mixing in patients with obesity, heart failure, and emphysema. Am Rev Respir Dis 1960; 82: 787-91.

35 Jense HG, Dubin SA, Silverstein PI, O'Leary-Escolas U. Effect of obesity on safe duration of apnea in anesthetized humans. Anesth Analg 1991; 72: 89-93.

36 Brodsky JB, Lemmens HJ, Brock-Utne JG, Vierra M, Saidman LJ. Morbid obesity and tracheal intubation. Anesth Analg 2002; 94: 732-6.

37 Davies KE, Houghton K, Montgomery JE. Obesity and day-case surgery. Anaesthesia 2001; 56: 1112-5.

38 Gold BS, Kitz DS, Lecky JH, Neuhaus JM. Unanticipated admission to the hospital following ambulatory surgery. JAMA 1989; 262: 3008-10.

39 Peevy KJ, Speed FA, Hoff CJ. Epidemiology of inguinal hernia in preterm neonates. Pediatrics 1986; 77: 246-7.

40 Stylianos S, Jacir NN, Harris BH. Incarceration of inguinal hernia in infants prior to elective repair. J Pediatr Surg 1993; 28: 582-3.

41 Cote CJ, Zaslavsky A, Downes JJ, et al. Postoperative apnea in former preterm infants after inguinal herniorrhaphy. A combined analysis. Anesthesiology 1995; 82 : 809-22.

42 Fisher DM. When is the ex-premature infant no longer at risk for apnea?(Editorial). Anesthesiology 1995; 82: 807-8

43 Allen GS, Cox CS Jr, White N, Khalil S, Rabb M, Lally $K P$. Postoperative respiratory complications in ex-premature infants after inguinal herniorrhaphy. J Pediatr Surg 1998; 33: 1095-8.

44 Welborn LG, Hannallah RS, Luban NL, Fink R, Ruttimann UE. Anemia and postoperative apnea in former preterm infants. Anesthesiology 1991; 74: 1003-6. 
45 Sims C, Johnson CM. Postoperative apnoea in infants. Anaesth Intensive Care 1994; 22: 40-5.

46 Welborn LG, Hannallah RS, Fink R, Ruttimann UE, Hicks JM. High-dose caffeine suppresses postoperative apnea in former preterm infants. Anesthesiology 1989; 71: 347-9.

47 Henderson-Smart DJ, Steer P. Prophylactic caffeine to prevent postoperative apnea following general anesthesia in preterm infants. Cochrane Database Syst Rev 2002; 4: CD000048.

48 Gunter JB, Watcha MF, Forestner JE, et al. Caudal epidural anesthesia in conscious premature and highrisk infants. J Pediatr Surg 1991; 26: 9-14.

49 Bouchut JC, Dubois R, Foussat C, et al. Evaluation of caudal anaesthesia performed in conscious ex-premature infants for inguinal herniotomies. Paediatr Anaesth 2001; 11: 55-8.

50 Welborn LG, Rice LJ, Hannallah RS, Broadman LM, Ruttimann UE, Fink $R$. Postoperative apnea in former preterm infants: prospective comparison of spinal and general anesthesia. Anesthesiology 1990; 72: 838-42.

51 Veverka TJ, Henry DN, Milroy MJ, et al. Spinal anesthesia reduces the hazard of apnea in high-risk infants. Am Surg 1991; 57: 531-4.

52 Sartorelli KH, Abajian JC, Kreutz JM, Vane DW. Improved outcome utilizing spinal anesthesia in highrisk infants. J Pediatr Surg 1992; 27: 1022-5.

53 Krane EJ, Haberkern CM, Jacobson LE. Postoperative apnea, bradycardia, and oxygen desaturation in formerly premature infants: prospective comparison of spinal and general anesthesia. Anesth Analg 1995; 80: 7-13.

54 Somri M, Gaitini L, Vaida S, Collins G, Sabo E, Mogilner $G$. Postoperative outcome in high-risk infants undergoing herniorrhaphy: comparison between spinal and general anaesthesia. Anaesthesia 1998; 53: 762-6.

55 Williams JM, Stoddart PA, Williams SA, Wolf AR. Post-operative recovery after inguinal herniotomy in ex-premature infants: comparison between sevoflurane and spinal anaesthesia. Br J Anaesth 2001; 86: 366-71.

56 Shenkman Z, Hoppenstein D, Litmanowitz I, et al. Spinal anesthesia in 62 premature, former-premature or young infants-technical aspects and pitfalls. Can J Anesth 2002; 49: 262-9.

57 Watcha MF, Thach BT, Gunter JB. Postoperative apnea after caudal anesthesia in an ex-premature infant. Anesthesiology 1989; 71: 613-5.

$58 \operatorname{Cox} R G$, Goresky $G V$. Life-threatening apnea following spinal anesthesia in former premature infants. Anesthesiology 1990; 73: 345-7.

59 Tait AR, Knight PR. The effects of general anesthesia on upper respiratory tract infections in children. Anesthesiology 1987; 67: 930-5.

60 Schreiner MS, O'Hara I, Markakis DA, Politis GD. Do children who experience laryngospasm have an increased risk of upper respiratory tract infection? Anesthesiology 1996; 85: 475-80.

61 Tait AR, Reynolds PI, Gutstein HB. Factors that influence an anesthesiologist's decision to cancel elective surgery for the child with an upper respiratory tract infection. J Clin Anesth 1995; 7: 491-9.

62 Tait AR, Malviya S, Voepel-Lewis T, Munro HM, Siewert $M$, Pandit $U A$. Risk factors for perioperative adverse respiratory events in children with upper respiratory tract infections. Anesthesiology 2001; 95: 299-306.

63 Parnis SJ, Barker DS, Van Der Walt JH. Clinical predictors of anaesthetic complications in children with respiratory tract infections. Paediatr Anaesth 2001; 11: 29-40.

64 Cohen MM, Cameron CB. Should you cancel the operation when a child has an upper respiratory tract infection? Anesth Analg 1991; 72: 282-8.

65 DeSoto H, Patel RI, Soliman IE, Hannallah RS. Changes in oxygen saturation following general anesthesia in children with upper respiratory infection signs and symptoms undergoing otolaryngological procedures. Anesthesiology 1988; 68: 276-9.

66 Levy L, Pandit UA, Randel GI, Lewis IH, Tait AR. Upper respiratory tract infections and general anaesthesia in children. Peri-operative complications and oxygen saturation. Anaesthesia 1992; 47: 678-82.

67 Rolf N, Cote CJ. Frequency and severity of desaturation events during general anesthesia in children with and without upper respiratory infections. J Clin Anesth 1992; 4: 200-3.

68 Tait AR, Pandit UA, Voepel-Lewis T, Munro HM, Malviya $S$. Use of the laryngeal mask airway in children with upper respiratory tract infections: a comparison with endotracheal intubation. Anesth Analg 1998; 86: 706-11.

69 Yentis SM, Levine MF, Hartley EJ. Should all children with suspected or confirmed malignant hyperthermia susceptibility be admitted after surgery? A 10-year review. Anesth Analg 1992; 75: 345-50.

70 Grinberg R, Edelist G, Gordon A. Postoperative malignant hyperthermia episodes in patients who received "safe" anaesthetics. Can Anaesth Soc J 1983; 30(3 Pt 1): 273-6.

71 Carr AS, Lerman J, Cunliffe M, McLeod ME, Britt BA. Incidence of malignant hyperthermia reactions in 2,214 patients undergoing muscle biopsy. Can J Anaesth $1995 ; 42$ : 281-6.

72 Larach $M G$, Localio AR, Allen GC, et al. A clinical grading scale to predict malignant hyperthermia susceptibility. Anesthesiology 1994; 80: 771-9.

73 Hackl W, Mauritz W, Winkler M, Sporn P, 
Steinbereithner $K$. Anaesthesia in malignant hyperthermia-susceptible patients without dantrolene prophylaxis: a report of 30 cases. Acta Anaesthesiol Scand 1990; 34: 534-7.

74 Malignant Hyperthermia Association of the United States. Medical FAQs. 2003; available from URL; http://www.mhaus.org/index.cfm/fuseaction/Conten t.Display/PagePK/MedicalFAQs.cfm.

75 Malignant Hyperthermia Association of Canada. Elective management of malignant hyperthermia susceptible patients. 2003; available from URL; http://www.mhacanada.org/MHA\%20Poster\%20txt.p df.

76 Karlet MC. Malignant hyperthermia: considerations for ambulatory surgery. J Perianesth Nurs 1998; 13: 304-12.

77 Strazis KP, Fox $A W$. Malignant hyperthermia: a review of published cases. Anesth Analg 1993; 77: 297-304.

78 Hopkins PM. Malignant hyperthermia: advances in clinical management and diagnosis. Br J Anaesth 2000; 85 118-28.

79 Wappler F. Malignant hyperthermia. Eur J Anaesthesiol 2001; 18: 632-52.

80 Wells DG, Bjorksten AR. Monoamine oxidase inhibitors revisited. Can J Anaesth 1989; 36: 64-74.

81 Martyr JW, Orlikowski CE. Epidural anaesthesia, ephedrine and phenylephrine in a patient taking moclobemide, a new monoamine oxidase inhibitor. Anaesthesia 1996; 51: 1150-2.

82 McFarlane HJ. Anaesthesia and the new generation monoamine oxidase inhibitors. Anaesthesia 1994; 49: 597-9.

83 Canadian Pharmacists Association. Compendium of Pharmaceuticals and Specialties. Eldepryl (selegiline) product monograph. 2003: 560-2.

84 Stack CG, Rogers P, Linter SP. Monoamine oxidase inhibitors and anaesthesia. A review. Br J Anaesth 1988; 60: 222-7.

85 Evans-Prosser CD. The use of pethidine and morphine in the presence of monoamine oxidase inhibitors. Br J Anaesth 1968; 40: 279-82.

86 Tordoff SG, Stubbing JF, Linter SP. Delayed excitatory reaction following interaction of cocaine and monoamine oxidase inhibitor (phenelzine). Br J Anaesth 1991; 66: 516-8.

87 Errando CL, Mateo E, Lopez-Alarcon D, Moliner S. Severe interactions with classic and selective monoamine oxidase inhibitors (Letter). Can J Anaesth 1998; 45: 706-7.

88 Boakes AJ, Laurence DR, Teoh PC, Barar FS, Benedikter $L T$, Prichard $B N$. Interactions between sympathomimetic amines and antidepressant agents in man. $\mathrm{Br}$ Med J 1973; 1: 311-5.
89 Ure DS, Gillies MA, James KS. Safe use of remifentanil in a patient treated with the monoamine oxidase inhibitor phenelzine. Br J Anaesth 2000; 84: 414-6.

90 Powell $H$. Use of alfentanil in a patient receiving monoamine oxidase inhibitor therapy (Letter). Br J Anaesth 1990; 64: 528-9.

91 O'Hara JF Jr, Maurer WG, Smith MP. Sufentanilisoflurane-nitrous oxide anesthesia for a patient treated with monoamine oxidase inhibitor and tricyclic antidepressant. J Clin Anesth 1995; 7: 148-50.

92 Fischer SP, Mantin R, Brock-Utne JG. Ketorolac and propofol anesthesia in a patient taking chronic monoamine oxidase inhibitors. J Clin Anesth 1996; 8: 245-7.

93 Doyle DJ. Ketamine induction and monoamine oxidase inhibitors. J Clin Anesth 1990; 2: 324-5.

94 Sides $C A$. Hypertension during anaesthesia with monoamine oxidase inhibitors. Anaesthesia 1987; 42: 633-5.

95 el Ganzouri AR, Ivankovich AD, Braverman B, $M c$ Carthy $R$. Monoamine oxidase inhibitors: should they be discontinued preoperatively? Anesth Analg 1985; 64: 592-6.

96 Ebrahim ZY, O'Hara J Jr, Borden L, Tetzlaff J. Monoamine oxidase inhibitors and elective surgery. Cleve Clin J Med 1993; 60: 129-30.

97 Abdi S, Fishman SM, Messner E. Acute exacerbation of depression after discontinuation of monoamine oxidase inhibitor prior to cardiac surgery. Anesth Analg 1996; 83: 656-7. 